\title{
Métodos de Ensino na Graduação de Enfermagem sobre Uso Prejudicial de Álcool: Implicações na Prática Profissional
}

\author{
Marjorie Ester Dias Maciel ${ }^{1 *}$, Divane de Vargas $^{2}$ \\ ${ }^{1}$ Doutora em Cuidado em Saúde pela Escola de Enfermagem de São Paulo - EEUSP. Membro do Núcleo de \\ Estudos e Pesquisas de Enfermagem em Adições - Álcool e Outras Drogas - NEPEAA/EEUSP. \\ ${ }^{2}$ Professor Associado do Departamento de Enfermagem Materno Infantil e Psiquiátrica da Escola de \\ Enfermagem de São Paulo (EE-USP). Líder do Núcleo de Estudos e Pesquisas de Enfermagem em Adições - \\ Álcool e Outras Drogas NEPEAA/EEUSP.
}

* Autora para correspondência: marjorieester@yahoo.com.br.

\section{RESUMO}

O presente relato procura refletir a respeito de como vem sendo desenvolvida a metodologia de ensino nos cursos de graduação em Enfermagem sobre o tema do uso prejudicial de álcool. Verifica-se que o ensino dessa temática está atrelado às tradicionais disciplinas relacionadas à saúde mental e à enfermagem psiquiátrica, nas quais ainda prevalece o enfoque psiquiátrico, tendo poucas horas dessas disciplinas dedicadas para o ensino desse assunto, o que é insuficiente para instrumentalizar futuros enfermeiros aptos para atuarem frente a essa questão. Assim, sugerem-se mudanças no modo de ensino e reformulação da grade curricular de enfermagem para que esse tema seja melhor contemplado na graduação.

Palavras-Chave: Ensino; Enfermagem; Educação em Enfermagem.

\begin{abstract}
The present report seeks to reflect on how the teaching methodology has been developed in undergraduate nursing about the issue alcohol harmful use. It is verified that the teaching of this issue is associated to the traditional disciplines related to mental health and psychiatric nursing, in which the psychiatric approach still prevails, with its few hours dedicated to the teaching of this subject, which is insufficient to support future nurses able to deal with this issue. Thus, it is suggested changes in the teaching methods and a reformulation of the nursing curriculum for proposing a better contemplation of this theme in the undergraduate course.
\end{abstract}

Keywords: Teaching; Nursing; Education in Nursing.

\section{Introdução}

Atualmente, verifica-se que o consumo de álcool de modo prejudicial à saúde tem aumentado na população brasileira, chegando a atingir cerca de $18,4 \%$, e, ao se levar em conta somente o sexo masculino, esse valor aumenta para 27,9\% (BRASIL, 2013). Essa alta prevalência na população repercute em todas as modalidades de atendimento dos serviços de saúde, gerando um grave problema nacional de saúde pública, o que implica altos investimentos dos órgãos governamentais para reverter essa situação, onerando principalmente a área de saúde (JOMAR, ABREU \& GRIEP, 2014).
O enfermeiro, enquanto trabalhador de saúde, em algum momento da sua vida profissional irá deparar com uma pessoa que faça uso abusivo ou nocivo de álcool, ou mesmo com dependentes de álcool (VARGAS, OLIVEIRA \& LUIS, 2010). Por esse motivo, os cursos de graduação em enfermagem devem contemplar em sua grade curricular um espaço para o ensino sobre os problemas relacionados ao uso prejudicial de álcool, pois o enfermeiro tem grande probabilidade de ser bem-sucedido ao desempenhar as ações de rastreamento e intervenção breve nos casos de transtornos relacionados ao uso de álcool (JOMAR \& ABREU, 2012). Para 
ter êxito nessas ações, o enfermeiro deve possuir um bom conhecimento técnico científico sobre as questões que permeiam os transtornos relacionados ao uso de álcool, e não fazer nenhum tipo de julgamento moral ou crítica à sua clientela que utiliza álcool (MACIEL \& PILLON, 2010).

Assim, os cursos de graduação em enfermagem devem proporcionar aos seus acadêmicos um aprendizado adequado através de conhecimento teórico-prático específico; afinal, deparam com a necessidade de preparar o graduando para atuar na prevenção a esses transtornos.

Diante disso, pretende-se neste relato realizar algumas considerações a respeito do ensino dessa temática no curso de graduação em enfermagem, visando a promover uma reflexão sobre esse ensino em específico, que muitas vezes, de acordo com a literatura, é negligenciado nos currículos dos cursos de graduação em enfermagem, bem como nos currículos dos demais cursos da área da Saúde (BONI et al., 2004).

\section{O Ensino sobre Álcool e Prática do Enfermeiro}

Desde os primórdios, a enfermagem procura atender aos interesses e necessidades da profissão e do seu contexto social, e, para isso, tem produzido um corpo de conhecimentos próprios (DOURADO, BEZERRA \& ANJOS, 2014). O processo de graduação em enfermagem deve estar em reformulação constante, baseado nas demandas de saúde da população. Assim, na emergência dos problemas decorrentes do uso excessivo de álcool como uma demanda de saúde da população brasileira que tem cada vez mais preocupado as autoridades governamentais e exigido maior atenção por parte dos profissionais de saúde, a enfermagem enquanto ciência deve estar atenta para preparar seus futuros profissionais a lidarem com essa realidade (JOMAR, ABREU \& GRIEP, 2014).

O enfermeiro possui uma posição privilegiada para identificar possíveis transtornos relacionados ao uso indevido de álcool, uma vez que ele é o profissional de saúde que mantém maior contato com os usuários dos serviços de saúde (VARGAS,
BITTENCOURT \& BARROSO, 2014). Logo, ele pode atuar nas duas vertentes da assistência de enfermagem: na primeira, de níveis de prevenção primária e secundária do uso prejudicial de álcool; e na segunda vertente, no nível de prevenção terciária, que é o ponto mais grave dos transtornos decorrentes do uso indevido de álcool, a dependência alcoólica (VARGAS, 2014).

Dessa forma, o enfermeiro tem a oportunidade de fazer uma intervenção breve para aqueles clientes que têm consumo de risco e prevenir o uso prejudicial de álcool, e realizar atividades de educação em saúde sobre moderação de álcool na comunidade. Quanto aos dependentes do álcool, o enfermeiro pode, através do processo de enfermagem, enfocar, na sua assistência, não só os aspectos físicos da doença, mas outras necessidades de caráter biopsicossocial do cliente, prevenindo também comorbidades, bem como realizar a entrevista motivacional para auxiliar o seu cliente no processo de mudança e na prevenção da recaída quando em tratamento para a dependência alcoólica (PILLON \& LARANJEIRA, 2005).

Sob esse aspecto, pressupõe-se que a graduação deva fornecer ao enfermeiro conhecimentos suficientes sobre o tema, destituí-lo de preconceitos sociais e respaldar suas ações assistenciais para o nível não especializado do sistema de saúde. No entanto, a literatura, tanto nacional quanto internacional, é unânime em afirmar que o ensino sobre uso de álcool e dependência alcoólica é insuficiente para subsidiar a prática do enfermeiro e desmistificar o preconceito que pesa sobre a pessoa alcoolista, fazendo com que o profissional mantenha atitudes negativas direcionadas a essa clientela (Idem, ibidem).

Esse fato pode ser explicado à medida que se concebe o ensino como produto da sociedade na qual está inserido, sendo ele determinado histórica e socialmente. Dessa maneira, ele reflete as posturas e valores de uma sociedade, servindo para manter a hegemonia das classes dominantes, preparando profissionais não para melhorar a realidade social, mas para atender as demandas de mercado dentro da óptica capitalista (FREIRE, 2004). 
Assim, o ensino sobre álcool e dependência alcoólica nos cursos de enfermagem depara-se com esse panorama, pois o alcoolismo é visto pela população em geral como um defeito moral (PELUSO \& BLAY, 2008), sendo rejeitado socialmente, implicando uma deficiência do ensino relativo a ele nas faculdades de enfermagem; adicionalmente, $o$ fato de o álcool ser uma droga socialmente aceita faz com que os riscos e danos inerentes ao uso abusivo/prejudicial sejam subestimados (MACIEL \& PILLON, 2010).

Além desse estigma social que chega ao meio acadêmico, o ensino sobre consumo disfuncional de álcool possui outros entraves que dificultam a sua abordagem para uma aprendizagem eficaz, sendo o maior deles a tradicional inserção desse conteúdo nas disciplinas de saúde mental ou de enfermagem psiquiátrica (BONI et al., 2004). Isso ocorre porque essa inserção mantém o conteúdo sobre transtornos relacionados ao álcool restritos ao enfoque psiquiátrico, acarretando a mesma problemática que ocorre com os demais conteúdos dessas disciplinas, que é a fragmentação e a dicotomia entre a teoria do ensino e a prática do enfermeiro (REINALDO \& PILLON, 2007).

Outro obstáculo que dificulta o aprendizado dos discentes de enfermagem é a insuficiência de horas dedicadas ao ensino sobre álcool, cerca de quatro a cinco horas durante toda a graduação (RASSOL \& RAWAF, 2008), e a ausência de articulação desses conteúdos com outras disciplinas, como, por exemplo, as relacionadas à saúde pública e à saúde do adulto com o enfoque específico de cada disciplina, o que daria um caráter transversal ao tema. Essa sugestão encontra-se ancorada na proposta do currículo integrado seguindo as Diretrizes Curriculares Nacionais do Curso de Graduação em Enfermagem de 7 de novembro de 2001 (BRASIL, 2001).

Diante desse contexto, perpetua-se a manutenção das dificuldades dos estudantes de enfermagem e do enfermeiro sobre os conteúdos relacionados ao uso de álcool (VARGAS, 2014). Frente a esse fato, é indiscutível e imperativa a necessidade de mudança no ensino sobre álcool, seu uso prejudicial e dependência alcoólica nos cursos de graduação em enfermagem, pois sabe-se que as tradicionais aulas teóricas expositivas atreladas às disciplinas de enfoque psiquiátrico são ineficazes para mudar esse contexto (PILLON \& LARANJEIRA, 2005).

É preciso inserir o discente na realidade da sua clientela com o objetivo da ampliação da interação cultural e da vivência da realidade desse problema social, para uma construção do conhecimento que seja de fato capaz de ser aplicável na resolução dos problemas de saúde da população (VASCONCELOS, 2004).

Assim, o docente não se deve limitar a "dissertar sobre conteúdos", mas deve problematizar com os discentes novas formas de compreensão do objeto de análise (VASCONCELOS, 2004), ou seja, entender os fatores, sejam eles de ordem social, cultural ou familiar, que impliquem risco para um consumo de modo prejudicial de álcool.

\section{Estratégias de Ensino sobre o Álcool}

Para o ensino de enfermagem sobre uso, abuso e dependência de álcool, não basta apenas haver uma carga horária excelente, porque, caso contrário, continuará formando apenas bons técnicos, distantes das pessoas portadoras de sofrimento ou dos problemas de saúde da população (BONI et al., 2004).

Portanto, é preciso que o estudante aprenda a ter uma boa interação com o paciente, que neste relato é o alcoolista ou usuário abusivo de álcool, sem recriminá-lo ou julgá-lo (LIMA, 2008). Para tanto, é necessário que o educando tome contato com o contexto cultural no qual a população está inserida. Uma boa oportunidade para que isso ocorra é durante os estágios curriculares, por meio de visitas domiciliares, já que durante essas há uma aproximação da teoria e prática, possibilitando ao aluno assistir o paciente e sua família nos diferentes níveis de prevenção, conhecendo a relação do paciente com o meio em que vive (PILLON \& LARANJEIRA, 2005).

Desse modo, não se terá somente o enfoque hospitalocêntrico, nem somente o da doença, pois o aprendizado deverá ser voltado para outros 
aspectos (RASSOL \& RAWAF, 2008). Assim, as faculdades de enfermagem devem deixar de ser "um lugar" exclusivo em que se aprende apenas o básico, reproduzindo o conhecimento dominante, para assumir o papel de apreendedoras e transformadoras da realidade da população (VASCONCELOS, 2008).

Para que o ensino desses conteúdos não fique restrito à saúde mental, deve haver uma correlação com outras disciplinas, tais como saúde coletiva, saúde pública, saúde do adulto, entre outras. Outra forma é ampliar a participação do educando no ensino, através do diálogo, provocando reflexão e trocas de ideias por meio de experiências pessoais fora do contexto de sala de aula (FREIRE, 2004).

Em outro extremo, alguns estudiosos da área defendem a implantação de uma disciplina denominada de alcoologia nos currículos de graduação dos cursos da área de Saúde, para que haja o enfoque de prevenção dos problemas relacionados ao álcool, redução de danos, recuperação, e promoção da saúde e qualidade de vida dos indivíduos que fazem uso excessivo ou dos dependentes de álcool (LIMA, 2008).

Todavia, independentemente de haver uma disciplina específica sobre consumo abusivo de álcool e dependência alcoólica, o ensino dessa temática deve ser repensado nos cursos de graduação de enfermagem para atender as necessidades de saúde da população.

\section{Considerações Finais}

$\mathrm{O}$ ensino sobre esse assunto nos cursos brasileiros de graduação em Enfermagem ainda é insuficiente para instrumentalizar futuros enfermeiros no que diz respeito a atuarem frente aos problemas relacionados ao uso prejudicial e crônico de álcool. É preciso repensar em como está ocorrendo a abordagem desse tema na graduação em Enfermagem, devendo haver uma abordagem interdisciplinar.

Espera-se que, com os problemas elencados neste relato e com o novo paradigma de ensino dado pelas Diretrizes Curriculares Nacionais do Curso de Graduação em Enfermagem, os docentes das disciplinas de Enfermagem Psiquiátrica e/ou de Saúde Mental possam refletir sobre suas práticas de ensino a respeito do tema, com o intuito de adequá-las às necessidades de saúde da clientela e de uma assistência de enfermagem de qualidade.

\section{Referências Bibliográficas}

BONI, Robison; PILON, Sandra Cristina; SANTOS, Elisangela; CAMATA, Marcio \& MACIEIRA, Marluce. "Os Conteúdos Álcool e Drogas no Ensino de Enfermagem da UFES: uma Análise Crítica". Revista Eletrônica de Enfermagem, Goiânia, vol. 6, n. 1, pp. 38-46, 2004.

BRASIL. Ministério da Saúde. Departamento de Vigilância de Doenças e Agravos Não Transmissíveis e Promoção à Saúde. Vigilância de Fatores de Risco e Proteção para Doenças Crônicas por Inquérito Telefônico (Vigitel). Brasília (DF): Ministério da Saúde, 2013.

BRASIL. Ministério da Educação. Conselho Nacional de Educação. Câmara de Educação Superior. Resolução CNE/CES n. 3, de 7 de novembro de 2001. Institui Diretrizes Curriculares Nacionais do Curso de Graduação em Enfermagem. Diário Oficial da União. Brasília, 9 nov. 2001, Seção 1, p. 37.

DOURADO, Sandra Beatriz Pedra Branca; BEZERRA, Cleanto Furtado \& ANJOS, Caio Cézar Nogueira. "Conhecimentos e Aplicabilidade das Teorias de Enfermagem pelos Acadêmicos". Revista de Enfermagem da UFSM, Santa Maria, vol. 4, n. 2, pp. 284-291, 2014.

FREIRE, Paulo. Pedagogia do Oprimido. Rio de Janeiro: Paz e Terra, 2004.

JOMAR, Rafael Tavares \& ABREU, Ângela Maria Mendes. "Intervenções Breves para Uso Problemático de Álcool: Potencial de Aplicação na Prática do Enfermeiro". Revista Enfermagem Uerj, Rio de Janeiro, vol. 20, n. 3, pp. 391-395, 2012.

; \& GRIEP, Rosane Harter. "Caracterização do Consumo de Álcool de uma População Adscrita à Estratégia Saúde da Família”. Escola Anna Nery Revista de Enfermagem, Rio de Janeiro, vol. 18, n. 1, pp. 96-100, 2014.

LIMA, M. B. Alcoologia: o Álcool na Perspectiva da Saúde Pública. Rio de Janeiro: Med BooK, 2008.

MACIEL, Marjorie Ester Dias \& PILLON, Sandra Cristina. "Grupo de Ajuda a Alcoolistas: a Educação em Saúde na Estratégia Saúde da Família". Cogitare Enfermagem, Curitiba, vol. 15, n. 3, pp. 552-5, 2010.

PELUSO, Érica de Toledo Piza \& BLAY, Sérgio Luís. "A Percepção Popular sobre Dependência Alcoólica". Rev. Bras. Psiquiatr. São Paulo, vol. 30, n. 1, pp. 19-24, 2008.

PILLON, Sandra Cristina \& LARANJEIRA, Ronaldo Ramos. "Formal Education and Nurses' Attitudes towards Alcohol and Alcoholism in a Brazilian Sample". São Paulo Medical Fournal, vol. 123, n. 4, pp. 175-180, 2005. 
RASSOOL, Hussein \& RAWAF, Salman. "Predictors of Educational Outcomes of Undergraduate Nursing Students in Alcohol and Drug Education". Nurse Education Today, Ediburgo, vol. 28, n. 6, pp. 691-701, 2008.

REINALDO, Amanda Márcia dos Santos \& PILLON, Sandra Cristina. "História da Enfermagem Psiquiátrica e a Dependência Química no Brasil: Atravessando a História para Reflexão". Escola Anna Nery Revista de Enfermagem, Rio de Janeiro, vol. 11, n. 4, pp. 688-693, 2007.

VARGAS, Divane. "Nurses' Personal Knowledge and Their Attitudes toward Alcoholism Issues: a Study of a Sample of Specialized Services in Brazil". Fournal of Nursing Education and Practice, vol. 4, n. 2, pp. 123-130, 2014.
; OLIVEIRA, Márcia Aparecida \& LUÍS, Margarita Antonia. "Atendimento ao Alcoolista em Serviços de Atenção Primária à Saúde: Percepções e Condutas do Enfermeiro". Acta Paulista de Enfermagem, São Paulo, vol. 23, n. 1, pp. 73-79, 2010.

; BITTENCOURT, Marina \& BARROSO, Lúcia. "Padrões de Consumo de Álcool de Usuários de Serviços de Atenção Primária à Saúde de um Munícipio Brasileiro". Ciência \& Saúde Coletiva, Rio de Janeiro, vol. 19, n. 1, pp. 17-25, 2014.

VASCONCELOS, Eymard Mourão. "Educação Popular: de uma Prática Alternativa a uma Estratégia de Gestão Participativa das Políticas de Saúde". Physis, João Pessoa, vol. 14, n. 1, pp. 67-83, 2004.

Publicado em 22/12/2017. 